Original Contribution

\title{
ASSESSMENT OF THE PERCENTAGES OF T-LYMPHOCYTE SUBSETS IN THE PERIPHERAL BLOOD OF MEDITERRANEAN SPOTTED FEVER PATIENTS
}

\author{
Iv. Baltadzhiev ${ }^{1}$, P. Pavlov ${ }^{2}$ \\ ${ }^{1}$ Department of Infectious Diseases, Parasitology and Tropical Medicine, Faculty of Medicine, \\ Medical University and St. George University Hospital, Plovdiv, Bulgaria \\ ${ }^{2}$ Department of Clinical Laboratory, Faculty of Pharmacy, Medical University and St. George \\ University Hospital, Plovdiv, Bulgaria
}

\begin{abstract}
PURPOSE: Mediterranean spotted fever (MSF) is a rickettsial disease. THE AIM was to evaluate the host immune response to Rickettsia conorii. MATERIAL AND METHODS: 62 patients were assigned into three groups: with mild, moderate or severe clinical forms of MSF. Controls were 32 healthy individuals. The diagnosis of MSF was confirmed by the indirect immunofluorescence assay. Immunophenotyping was performed using Epics XL-MCL Coulter. RESULTS: The percentage of immune competent $(\mathrm{CD} 3+)$ cells decreased, whereas that of helper/inducer $(\mathrm{CD} 3+\mathrm{CD} 4+)$ and suppressor/cytotoxic $(\mathrm{CD} 3+\mathrm{CD} 8+)$ did not change compared to controls. All three T-cell subset percentages did not parallel the disease severity. Naïve T-cells (CD4+CD45RA+) showed reduced levels, whereas activated memory $(\mathrm{CD} 4+\mathrm{CD} 45 \mathrm{RO}+) \mathrm{T}$-cells did not change significantly. The percentage of activated (CD3+HLA-DR+) T-cells increased regardless of the disease severity, till the rise of stimulatory molecules (CD38+total) matched the disease severity forms. The percentage of costimulatory CD28-molecules corresponded to the disease severity as their levels increased significantly in mild forms and showed an evident downward trend towards the severe ones. CONCLUSION: Reduced T-lymphocyte subsets are likely related to trans-migration into perivascular inflammatory foci. The increased percentage of T-lymphocytes armed with stimulatory molecules probably reflects the mobilization of cell-mediated immune response in the healing process.
\end{abstract}

Key words: Mediterranean spotted fever, clinical forms by severity, T-lymphocyte subsets, percentage, flow cytometriy, immunophenotyping

\section{INTRODUCTION}

Mediterranean spotted fever (MSF) is caused by Rickettsia conorii subsp. conorii and is transmitted to humans by the bite of the brown dog tick Rhipicephalus sanguineus. It is one of the most widespread vector-borne rickettsial diseases in the endemic areas - the countries along the Mediterranean Coast, North and Sub-Saharan Africa, as well as in Central and Southern Europe (1). Due to the intense

Correspondence to: Dr. Ivan Baltadzhiev, Department of Infectious Diseases, Parasitology and Tropical Medicine, Faculty of Medicine, Medical University, 15A Vassil Aprilov Blvd., 4002 Plovdiv, Bulgaria, tel./fax:

+35932268341/+35932602851, e-mail:

ivan_balt@yahoo.com development of tourism and improved communications, a growing number ofimported cases to non-endemic areas and countries have been reported (2). Rickettsiae invade and multiply in the microvascular endothelium of small blood vessels capillaries, venules and arterioles. As a result, the vascular endothelium transforms into an activated inflammatory phenotype with the secretion of cytokines, production of chemoattractants, expression of adhesion receptors, and endothelial ligands to leukocyte integrins $(3,4)$. These processes result in white blood cell diapedesis into the perivascular space, adjacent to the pathogen's location. The recruitment of immune lymphocytes from the blood circulation towards the infection focus leads to the formation of perivascular 
inflammatory infiltrates and is related to the clearance of rickettsiae (5). An intense involvement of vital organ system microvasculature may result in disseminated vasculitis, severe disease course and lethal outcome. There is evidence that endothelial activation is more pronounced in severe forms of $\operatorname{MSF}(4,6)$. At the same time, transmigration of immune blood cells to the infection focus may induce lymphocyte imbalance in the peripheral blood of MSF patients. The evaluation of the percentages of T-lymphocyte subsets in the peripheral blood might serve as an important determinant of the disease course (7-9).

THIS STUDY AIMED at investigating the percentages of T-lymphocyte subsets in the peripheral blood of patients with MSF, attempting to assess the host immunity in the acute stage of the disease.

\section{MATERIALS AND METHODS}

1. SELECTION CRITERIA: The patients were enrolled in our study based on the following criteria:

Inclusion criteria - presence of pathognomonic eschar (tache noire) and febrile illness with flulike symptoms prior to the onset of typical maculopapular rash; confirmation of MSF diagnosis at the Reference Laboratory for Rickettsioses at the Military Medical Academy in Sofia, Bulgaria, by the indirect immunofluorescent assay (IFA) to a specific R.conorii antigen (IFA test Rickettsia conoriSpot IF, BioMerieux, Marcy L'Etoile, France) (10). IgG titres of $\geq 128$ and /or IgM titres of $\geq 64$ were considered indicative of infection with R.conorii; lack of antibiotic treatment prior to hospitalization.

Exclusion criteria - patients with coexisting severe acute or chronic medical conditions.

2. DISEASE SEVERITY CRITERIA: The severity of MSF was determined according to the criteria, developed and reported by our team in our previous research works (9). According to these criteria, the clinical forms of MSF were divided into mild, moderate, severe and malignant. In the present study, severe and malignant forms both were referred to as severe forms because of their similarity.

3. STUDY POPULATION: T-lymphocyte immunophenotyping was performed on day one following the onset of rash, prior to initiation of appropriate antibiotic therapy in the peripheral blood of 62 patients with MSF (29 males and 33 females, mean age $52.66 \pm$ 2.22 years). Subjects were assigned into three strictly age and sex matched groups based on the severity of disease: 20 patients ( 9 males, 11 females, mean age $49.18 \pm 3.05$ years) presented with mild MSF; 20 patients (10 males, 10 females, mean age $52.77 \pm 1.9$ years) had the disease in its moderate form; 22 patients (10 men, 12 women, mean age $50.98 \pm$ 3.4 years) suffered from severe form of the disease. Controls were 32 age and sex matched healthy individuals.

\section{4.}

FLOW

CYTOMETRY

IMMUNOPHENOTYPING: Blood samples for quantitative determination of T-lymphocyte subsets were taken in the acute stage - at the disease climax and samples were tested promptly using flow cytometric analysis. EDTA-K3 blood collection tubes were applied for whole venous blood collection. Leukocyte counts and white blood cell differentiation were performed on Sysmex SE 9500 (Japanese hematological analyzer). Ten micro liters $(\mu \mathrm{l})$ specific monoclonal antibodies were added to $100 \mu \mathrm{l}$ whole blood samples in siliconized test tubes $(12 \times 75 \mathrm{~mm})$. Prior to flowcytometry, specimens were processed using automated Multi-Q-Prep (Coulter). Immunophenotyping of the lymphocyte subsets was carried out by Epics XL-MCL Coulter flow cytometer, USA. An expanded panel was attached, using a twocolor analyzer with FITC and RD1 labelled monoclonal antibodies, provided by the Beckman-Coulter Company. The counts of the following lymphocyte subsets were determined: CD3-FITC/CD4-RD1 and CD3FITC/CD8-RD1 (immune competent Tlymphocytes and their subsets - helper/inducer and suppressor/cytotoxic); CD3-FITC/HLADR-RD1 (activated mature T-lymphocytes); CD4-FITC/ CD45RA-RD1 (naive CD4 Tlymphocytes); CD4-FITC/CD45RO-RD1 (memory CD4 T-lymphocytes); CD8FITC/CD38-RD1 (cell activation marker CD38); and CD8-FITC/CD28-RD1 (CD28 costimulatory molecule for CD4+ and/or CD8+ T-lymphocyte activation). Results were expressed as absolute cell counts per $\mu \mathrm{l}$ and as percentages. In the course of flow cytometric analysis, CD14-RD1/CD45-FITC was used for control and optimization of light scattering in order to achieve precise phenotyping of leukocytes. The corresponding MsIgG1FITC/MsIgG1-RD1 and MsIgG1FITC/MsIgG2a-RD1 were applied for isotope 
control. The Control materials, through which the results quality was controlled in the optimal range were: DNAcheck, Standart-Brite and Cyto-Trol Control Cells.

5. STATISTICAL ANALYSIS: Statistical analysis was performed using SPSS 15.0.1 software package. Because of an absence of Gaussian distribution of the variables, the differences between two mean values were evaluated for statistical significance using the non-parametric Mann-Whitney $U$ rank-sum test for not normally distributed variables to compare the mean values of two groups, and by Kruskal-Wallis nonparametric ANOVA test to compare the mean values of more than two groups. Results were presented as Mean \pm SEM. Two-tailed $\mathrm{P}<0.05$ was considered as statistically significant.

\section{IMMUNE-COMPETENT T-} LYMPHOCYTES AND THEIR SUBSETS:

Based on cluster

differentiation (CD) of lymphocyte bound molecules, the following cells were objects of investigation in our study: cells expressing the signal component of the T-cell receptor (TCR) complex - CD3, cells expressing the MHC class II co-receptor - CD4, and cells expressing the MHC class I co-receptor - CD8. The percentage of the immune-competent (CD3+) Tlymphocytes was reduced significantly in comparison to controls, whereas that of the helper/inducer $\quad(\mathrm{CD} 3+\mathrm{CD} 4+) \quad$ and suppressor/cytotoxic (CD3+CD8+) did not change substantially compared to controls. CD4/CD8 ratio showed no difference to the controls (Table 1). No correlation was found between the above T-lymphocyte subsets and the MSF severity forms (Table2).

\section{RESULTS}

Table 1. T-lymphocyte subset percentage in the peripheral blood of patients with Mediterranean spotted fever and control group

\begin{tabular}{|c|c|c|c|}
\hline $\begin{array}{l}\text { T-lymphocyte } \\
\text { subsets }\end{array}$ & $\begin{array}{l}\text { Patients } \quad n=62 \\
\text { Mean } \pm \text { SEM }\end{array}$ & $\begin{array}{l}\text { Controls } \mathrm{n}=32 \\
\text { Mean } \pm \text { SEM }\end{array}$ & $\begin{array}{l}P \\
\text { two tailed }\end{array}$ \\
\hline $\mathrm{CD3}^{+}$total & $69.39 \pm 1.61$ & $73.39 \pm 1.14$ & $p<0.05$ \\
\hline $\mathrm{CD3}^{+} \mathrm{CD4}^{+}$ & $39.92 \pm 1.36$ & $39.46 \pm 1.31$ & $p>0.05$ \\
\hline $\mathrm{CD3}^{+} \mathrm{CD8}^{+}$ & $28.17 \pm 1.57$ & $26.87 \pm 1.24$ & $\mathrm{p}>0.05$ \\
\hline CD4/CD8 & $1.60 \pm 0.12$ & $1.42 \pm 0.08$ & $p>0.05$ \\
\hline $\mathrm{CD3}^{+} \mathrm{HLA}-\mathrm{DR}^{+}$ & $6.66 \pm 0.79$ & $2.57 \pm 0.31$ & $\mathrm{p}<0.0001$ \\
\hline $\mathrm{CD8}^{-} \mathrm{CD}^{+}{ }^{+}$ & $24.36 \pm 1.82$ & $10.28 \pm 0.88$ & $\mathrm{p}<0.0001$ \\
\hline $\mathrm{CD8}^{+} \mathrm{CD}^{+}{ }^{+}$ & $9.55 \pm 1.15$ & $1.19 \pm 0.14$ & $\mathrm{p}<0.0001$ \\
\hline $\mathrm{CD}^{2}{ }^{+}$total & $33.91 \pm 2.33$ & $11.47 \pm 0.96$ & $\mathrm{p}<0.0001$ \\
\hline $\mathrm{CD8}^{-} \mathrm{CD}^{+} \mathrm{s}^{+}$ & $15.94 \pm 1.54$ & $12.36 \pm 2.02$ & $p>0.05$ \\
\hline $\mathrm{CD8}^{+} \mathrm{CD}^{-} \mathrm{8}^{+}$ & $3.04 \pm 0.45$ & $1.86 \pm 0.48$ & $p>0.05$ \\
\hline $\mathrm{CD}{ }^{+}$Total & $18.98 \pm 1.80$ & $14.22 \pm 2.44$ & $p>0.05$ \\
\hline $\mathrm{CD4}^{+} \mathrm{CD}^{25 \mathrm{RO}^{+}}$ & $22.75 \pm 1.52$ & $20.27 \pm 1.18$ & $p>0.05$ \\
\hline $\mathrm{CD4}^{+} \mathrm{CD}^{25 \mathrm{RA}^{+}}$ & $8.72 \pm 1.34$ & $14.02 \pm 1.37$ & $\mathbf{p}<0.01$ \\
\hline
\end{tabular}

\section{MARKERS OF ACTIVATION OF IMMUNE-COMPETENT T-LYMPHOCYTE SUBSETS:}

a) CD3+HLA-DR+ phenotype identify the activated immunocompetent T-lymphocytes. Both CD4+ helper/inducer, and CD8+ suppressor/cytotoxic T-cells express HLA-DR molecules as an important surface activation marker. The CD3+HLA-DR+ activated mature $\mathrm{T}$ lymphocyte percentage increased significantly when compared to controls. This rise was significant in all three MSF severity forms. We failed to detect statistically significant differences between the above Tlymphocyte subset and the MSF severity forms - Table 2. b) $\mathrm{CD38}$ (cyclic ADP ribose hydrolase) is a type II glycosylated membrane protein that is expressed in a number of immune cells: CD4+, $\mathrm{CD} 8+, \mathrm{B}$ and NK. It plays a role in cellular adhesion, signal transduction and calcium signal regulation (11). CD38 co-stimulatory proteins are expressed selectively in higher amounts in the process of activation of mature T-cell subsets with increased capacity of IL-2 and IFN- $\gamma$ cytokine production. There are reports linking CTL (cytotoxic T-lymphocyte) activity to the CD38 molecule. This emphasizes the role of these proteins in the activation and differentiation of $\mathrm{T}$ lymphocytes. We have found out that the percentage of all CD38+ expressing cells 
(CD38+total), as well as the CD8+CD38+ and CD8-CD38+ subsets increased in patients with MSF, compared to controls. The rise was especially pronounced in the $\mathrm{CD} 8+\mathrm{CD} 38+\mathrm{T}$ lymphocyte subset - more than 8 times that of the controls - Table 1. An increase in the percentage of CD38+ total, CD8-CD38+ and CD8+CD38+ cell subsets to the controls was noted in all three studied clinical forms of MSF. A reliable upward trend from mild to severe MSF forms was found out in CD38+ total and CD8-CD38+ subset percentages. On the contrary, such tendency was not detected regarding the cytotoxic $\mathrm{CD} 8+\mathrm{CD} 38+\mathrm{T}$-cells Table 2.

c) CD28 cell surface accessory molecules are expressed in a large group of T-lymphocytes. These molecules provide co-stimulatory signals necessary for CD4 and CD8 naïve cells activation. Through the CD28 antigen (CD28Ag) T-lymphocytes receive a potent stimulus to produce interleukins, especially IL2 and IL-6 (12). In our study CD28+total, CD8-CD28+ and CD8+CD28+ T-lymphocyte subset percentages showed a tendency to increase, however, differences with the control levels did not reach a statistical significance Table 1. The percentages of all three T-cell subsets increased significantly only in patients with mild forms of MSF compared to the control group - Table 2. Each of the CD28+ T-lymphocyte subsets showed a pronounced downward trend from light to severe form of the disease. In all cases, the CD28+ Tlymphocyte subset percentage was significantly lower in severe forms of the disease compared to the mild forms - Table 2.

\section{MEMORY CD4+CD45RO+ AND NAÏVE CD4+CD45RA+ T-LYMPHOCYTE SUBSETS:}

The naïve T-cells (CD4+CD45RA+) showed a reduced level, with a tendency to decrease in the severe forms of the disease - Tables 1 and 2. The activated memory (CD4+CD45RO+) Tcell subsets did not change significantly compared to the controls (Table 1) and a reliable increase was documented only in moderate MSF forms - Table 2. In comparing the CD4+CD45RO+ as well CD4+CD45RA+ subset percentages in MSF mild and moderate forms of severity, the established differences did not reach a statistical significance. The only exception was the severe disease forms. Both T-lymphocyte subsets exhibited a downward trend from mild to severe MSF forms - Table 2.

\section{DISCUSSION}

It is well known that the active cellular immune responses play a crucial role in the human defense mechanisms against pathogenic rickettsiae (13-18). Investigations of the role of $\mathrm{CD} 8+\mathrm{T}$-cells in antirickettsial immunity have shown that endothelium plays an important role in the antigen presentation (1920). There is evidence that endothelial antigen presentation induces activation and proliferation of memory T-cells, as well as antigen specific transmigration of $\mathrm{T}$ lymphocytes in the perivascular infiltrates. Perivascular CD4+ and CD8+ T-lymphocytes, macrophages and dendritic cells are cytokine producers, thus activating endothelial antirickettsial potential $(21,22-25)$. However, current investigations of $\mathrm{T}$-cell subsets in the peripheral blood of patients with MSF are scarce $(8,15,16,26-29)$. A probable explanation for the reduced percent of CD3+ T-cells might be the immune cell adherence to the vascular endothelium and the subsequent transmigration into the inflammatory foci (27, 28) Investigations of the perivascular infiltrate cell composition provided evidence for this understanding $(19,20)$. Apoptosis could also play a role in the immune cell percent depression in the blood circulation $(15,27)$. Despite the critical role of the CD8+ Tlymphocytes in the clearance of rickettsial infection (18), the percentage of CD4+ and CD8+ T cells in the peripheral blood of MSF patients does not differ significantly from the controls. The CD4/CD8 ratio is within the reference range and could not be used as a clinical predictor in the acute stage of the disease. Interestingly, in contrast to the absolute amount of these T-lymphocyte subsets in the peripheral blood of MSF patients (26), the percentage ratios of all basic $\mathrm{T}$-cell subsets (CD3+, CD4+, CD8+) did not correlate with the disease's severity. Similar inconsistencies, regarding some pathological conditions have been reported by other authors as well (7). It is believed that in cases, when specific immune cells are generated in response to antigen stimulation, the balance is maintained by the regulated apoptosis of other T-lymphocyte subsets (7). Probably, homeostatic mechanisms prevent the imbalance in the percentage ratios of the above basic T-cell subsets during the acute stage of MSF. 
Table 2. T-lymphocyte subset percentages in the peripheral blood of patients with Mediterranean spotted fever of various

\begin{tabular}{|c|c|c|c|c|c|c|c|}
\hline \multirow{3}{*}{$\begin{array}{l}\text { T-lymphocyte } \\
\text { subsets }\end{array}$} & \multirow{3}{*}{$\begin{array}{c}\text { Control } \\
\mathbf{n}=\mathbf{3 2} \\
\text { Mean } \pm \text { SEM }\end{array}$} & \multirow{3}{*}{$\begin{array}{c}\text { Mild form }^{1} \\
\quad \mathbf{n}=\mathbf{2 0} \\
\text { Mean } \pm \text { SEM }\end{array}$} & \multirow{3}{*}{$\begin{array}{c}\text { Moderate f-m } \\
\quad n=20 \\
\text { Mean } \pm \text { SEM }\end{array}$} & \multirow{3}{*}{$\begin{array}{c}\text { Severe form } \\
\quad \mathbf{n}=22 \\
\text { Mean } \pm \text { SEM }\end{array}$} & \multicolumn{3}{|c|}{$P$ (two tailed) } \\
\hline & & & & & $\mathrm{P}$ mild/control & P moder./contr & P severe/contr \\
\hline & & & & & $\begin{array}{l}\mathrm{P}^{1-2} \\
\text { mild/moderate }\end{array}$ & $\begin{array}{l}\mathrm{P}^{2-3} \\
\text { moder./severe }\end{array}$ & $\begin{array}{l}\mathrm{P}^{1-3} \\
\text { mild/severe }\end{array}$ \\
\hline $\mathrm{CD3}^{+}$total & $73.39 \pm 1.14$ & $66.27 \pm 4.59$ & $71.39 \pm 2.52$ & $69.48 \pm 1.81$ & $\begin{array}{l}\mathrm{p}>0.05 \\
\mathrm{P}^{1-2}>0.05\end{array}$ & \begin{tabular}{|l}
$\mathrm{p}>0.05$ \\
$\mathrm{P}^{2-3}>0.05$
\end{tabular} & $\begin{array}{l}\mathrm{p}>0.05 \\
\mathrm{P}^{1-3}>0.05\end{array}$ \\
\hline $\mathrm{CD3}^{+} \mathrm{CD4}^{+}$ & $39.46 \pm 1.31$ & $41.45 \pm 2.67$ & $40.84 \pm 2.10$ & $37.98 \pm 2.43$ & $\begin{array}{l}\mathrm{p}>0.05 \\
\mathrm{P}^{1-2}>0.05\end{array}$ & $\begin{array}{l}\mathrm{p}>0.05 \\
\mathrm{P}^{2-3}>0.05\end{array}$ & $\begin{array}{l}\mathrm{p}>0.05 \\
\mathrm{P}^{1-3}>0.05\end{array}$ \\
\hline $\mathrm{CD3}^{+} \mathrm{CD8}^{+}$ & $26.87 \pm 1.24$ & $30.17 \pm 4.33$ & $26.77 \pm 2.78$ & $28.23 \pm 1.53$ & $\begin{array}{l}\mathrm{p}>0.05 \\
\mathrm{P}^{1-2}>0.05\end{array}$ & \begin{tabular}{|l|}
$\mathrm{p}>0.05$ \\
$\mathrm{P}^{2-3}>0.05$
\end{tabular} & $\begin{array}{l}\mathrm{p}>0.05 \\
\mathrm{P}^{1-3}>0.05\end{array}$ \\
\hline $\mathrm{CD3}^{+}{ }^{+} \mathrm{LA}-\mathrm{DR}^{+}$ & $2.57 \pm 0.31$ & $7.02 \pm 1.77$ & $6.43 \pm 1.24$ & $6.65 \pm 1.34$ & $\begin{array}{l}\mathbf{p}<\mathbf{0 . 0 5} \\
\mathrm{P}^{1-2}>0.05\end{array}$ & $\begin{array}{l}\mathbf{p}<\mathbf{0 . 0 1} \\
\mathrm{P}^{2-3}>0.05\end{array}$ & $\begin{array}{l}\mathbf{p}<\mathbf{0 . 0 1} \\
\mathrm{P}^{1-3}>0.05\end{array}$ \\
\hline $\mathrm{CD8}^{-\mathrm{CD}^{2} 8^{+}}$ & $10.28 \pm 0.88$ & $17.03 \pm 1.86$ & $22.93 \pm 1.26$ & $31.41 \pm 3.18$ & \begin{tabular}{|l|}
$\mathbf{p}<0.01$ \\
$P^{1-2}<0.05$
\end{tabular} & \begin{tabular}{|l|}
$\mathbf{p}<0.0001$ \\
$\mathrm{P}^{2-3}<0.05$
\end{tabular} & $\begin{array}{l}<0.0001 \\
P^{1-3}<0.001\end{array}$ \\
\hline $\mathrm{CD8}^{+} \mathrm{CD}^{+}{ }^{+}$ & $1.19 \pm 0.14$ & $9.25 \pm 2.28$ & $12.13 \pm 2.57$ & $8.09 \pm 1.34$ & $\begin{array}{l}\mathbf{p}<\mathbf{0 . 0 1} \\
\mathrm{P}^{1-2}>0.05\end{array}$ & $\begin{array}{l}\mathbf{p}<\mathbf{0 . 0 1} \\
\mathrm{P}^{2-3}>0.05\end{array}$ & $\begin{array}{l}\mathbf{p}<\mathbf{0 . 0 0 0 1} \\
\mathrm{P}^{1-3}>0.05\end{array}$ \\
\hline CD38 $^{+}$total & $11.47 \pm 0.96$ & $26.28 \pm 3.87$ & $35.07 \pm 3.10$ & $39.50 \pm 3.75$ & \begin{tabular}{|l|}
$\mathbf{p}<0.01$ \\
$\mathrm{P}^{1-2}<0.05$
\end{tabular} & $\begin{array}{l}\mathbf{p}<\mathbf{0 . 0 0 0 1} \\
\mathrm{P}^{2-3}>0.05\end{array}$ & $\begin{array}{l}\mathbf{p}<0.0001 \\
\mathbf{P}^{1-3}<0.001\end{array}$ \\
\hline $\mathrm{CD8}^{-} \mathrm{CD}^{+}{ }^{+}$ & $12.36 \pm 2.02$ & $20.87 \pm 3.09$ & $15.35 \pm 1.69$ & $12.24 \pm 2.22$ & $\begin{array}{l}\mathbf{p}<\mathbf{0 . 0 5} \\
\mathrm{P}^{1-2}>0.05\end{array}$ & $\begin{array}{l}\mathrm{p}>0.05 \\
\mathrm{P}^{2-3}>0.05\end{array}$ & $\begin{array}{l}\mathrm{p}>0.05 \\
\mathbf{P}^{\mathbf{1}-\mathbf{3}}<\mathbf{0 . 0 5}\end{array}$ \\
\hline $\mathrm{CD8}^{+} \mathrm{CD28}^{+}$ & $1.86 \pm 0.48$ & $4.72 \pm 0.96$ & $2.51 \pm 0.59$ & $1.99 \pm 0.50$ & $\begin{array}{l}\mathbf{p}<\mathbf{0 . 0 5} \\
\mathrm{P}^{1-2}>0.05\end{array}$ & $\begin{array}{l}\mathrm{p}>0.05 \\
\mathrm{P}^{2-3}>0.05\end{array}$ & $\begin{array}{l}\mathrm{p}>0.05 \\
\mathbf{P}^{\mathbf{1}-3}<\mathbf{0 . 0 5}\end{array}$ \\
\hline $\mathrm{CD}^{2}{ }^{+}$total & $14.22 \pm 2.44$ & $25.59 \pm 3.19$ & $17.86 \pm 2.18$ & $14.22 \pm 2.64$ & \begin{tabular}{|l|}
$\mathbf{p}<\mathbf{0 . 0 1}$ \\
$\mathrm{P}^{1-2}>0.05$
\end{tabular} & $\begin{array}{l}\mathrm{p}>0.05 \\
\mathrm{P}^{2-3}>0.05\end{array}$ & $\begin{array}{l}\mathrm{p}>0.05 \\
\mathbf{P}^{\mathbf{1}-3}<\mathbf{0 . 0 5}\end{array}$ \\
\hline $\mathrm{CD4}^{+} \mathrm{CD}^{-\mathrm{ROO}^{+}}$ & $20.27 \pm 1.18$ & $23.67 \pm 2.97$ & $26.33 \pm 2.26$ & $19.60 \pm 2.31$ & $\begin{array}{l}\mathrm{p}>0.05 \\
\mathrm{P}^{1-2}>0.05\end{array}$ & $\begin{array}{l}\mathbf{p}<\mathbf{0 . 0 5} \\
\mathrm{P}^{2-3}>0.05\end{array}$ & $\begin{array}{l}p>0.05 \\
\mathbf{P}^{\mathbf{1 - 3}}<\mathbf{0 . 0 5}\end{array}$ \\
\hline $\mathrm{CD4}^{+} \mathrm{CD45RA}^{+}$ & $14.02 \pm 1.37$ & $11.20 \pm 2.53$ & $8.58 \pm 3.19$ & $6.75 \pm 1.56$ & $\begin{array}{l}\mathrm{p}>0.05 \\
\mathrm{P}^{1-2}>0.05\end{array}$ & $\begin{array}{l}\mathrm{p}>0.05 \\
\mathrm{P}^{2-3}>0.05\end{array}$ & $\begin{array}{l}\mathrm{p}<0.01 \\
P^{1-3}<0.05\end{array}$ \\
\hline
\end{tabular}


An attempt was made to evaluate the markers associated with T-cell activation - HLA-DR expression, as an early signal for the host response to the rickettsial antigen. It was found out that the activated CD3+/HLA-DR+ Tlymphocyte percent increased in all patients with MSF, as well as in different severity forms of the disease, presumably contributing to the development of an adequate immune response against the rickettsial invasion. Some researchers have reported similar data $(8,26)$, however, other authors report opposite results which indicates that further investigations are required to establish whether the immune activation represents an effective host response against rickettsiae (28).

The population of CD8+ T-lymphocytes might have an effector function in antigen specific dependency of CD38 $(29,30)$. In this respect, CD8+CD38+ T-cells seemed to act as activated lymphocytes with increased effector potential, i.e. cytotoxic T-lymphocytes (CTL). The functional loss of CD38 molecules has been related to metabolic disturbances and damaged immune responses (31). In our study, the percentages of the immune cell subsets, expressing these markers (CD38+ total, CD8CD38+ and CD8+CD38+) in patients with MSF as a whole, and in patients with different severity forms of the disease increased significantly compared to controls and their values increased in parallel to the severity of the disease. Our results suggest mobilization and activation of the cells, bearing CD38 molecules and especially the effector $\mathrm{CD}^{+} \mathrm{CD} 38^{+} \mathrm{T}$-lymphocytes in the response against the intracellular pathogen $R$. conorii. Correlation with the disease severity supports this suggestion. Other researchers of the immune mechanisms of MSF report similar data (29).

CD28 acts as a receptor for B7.1 (CD80) and B7.2 (CD86) co-stimulatory molecules, constitutively expressed on the surface of antigen presenting cells (APCs). It is suggested that within the CD8+ T-lymphocyte subsets, the expression of $\mathrm{CD} 28 \mathrm{Ag}$ is related to cytotoxic T-cells (CD8+CD28+) and the lack of $\mathrm{CD} 28 \mathrm{Ag}$ is related to $\mathrm{T}$ cell-suppressor activity $(32,33)$. CD28-B7 co-stimulation is necessary and sufficient for the generation of MHC class I specific CTL in the absence of CD4+helper T-cells. These interactions induce secretion of IL-2 by the precursors of CD8+Tcells, thus allowing proliferation of antigen specific CTL $(12,34)$. Two different signals are necessary for CD8+ $\mathrm{T}$ cell activation: one antigen specific mediated by TCR, and one accessory, provided through CD28-B7 interactions $(35,36)$. We observed an increase in the percentage of CD28-tagged T-cells in MSF patients, without the difference being statistically significant. A significant increase in the percentage of CD28-tagged Tlymphocytes was observed only in mild MSF clinical forms. Based on the characteristics of CD28Ag, it could be assumed that the percentage rise in the studied cell subsets was related to the endothelial presentation of rickettsial antigens to the effectors' cells (37). This process might result in an increase in the quantity of accessory molecules providing costimulatory signals to the naïve $\mathrm{T}$ lymphocytes, transforming them either into CD8+CD28+ CTL, or in activated CD4+TH1 effectors $(12,21)$. It is possible that in severe forms of MSF, certain amounts of CD8+CD28+, and CD8-CD28+ T-cells transmigrate in the surrounding inflammatory tissues, forming perivascular infiltrates, thus determining their composition. Apart from the above mentioned mechanism, apoptosis and destruction of the $\mathrm{CD} 28$ antigens (CD8+CD28), as receptors of co-stimulatory signals by the APCs also seems involved. It seems likely that these processes were more pronounced in severe MSF, therefore in mild clinical forms stand the best quantitative increase of these subsets. The regulatory properties of $\mathrm{CD} 28$ proteins could partly explain the results as well (38). Finally, the increase of CD28 molecules in mild forms of MSF might present a predictor of milder course of the disease. In the available literature, we were unable to find data on $\mathrm{CD} 8+\mathrm{CD} 28+\mathrm{T}$-cell subset in the rickettsial diseases and especially in MSF. However, there is data about a dramatic surge and markedly increased number and percentage of CD8+T-cells missing CD28 (CD8+CD28-) expression in HIV/AIDS patients, associated with the progression of the disease. Both the number and percentage of CD8+ T cells lacking surface CD28 expression increased dramatically during HIV infection (39). This suggests that effective immune responses maintain a pool of potential effector cells within the CD8+CD28+ T-cell population, whereas ineffective responses inexorably shift to $\mathrm{CD} 8+\mathrm{CD} 28$ - predominance. In severe MSF cases, we did not observe CD8+CD28+ T-cell 
loss (which could be related to $\mathrm{CD} 8+\mathrm{CD} 28^{-} \mathrm{T}$ lymphocyte prevalence and ineffective immune response): the percentage of CD8+CD28+ T-cells was close to that of the controls, despite the downward trend towards the severe MSF forms. Based on the above mentioned, we believe, that in general, our study confirms the favorable course of MSF, even in severe forms of the disease.

CD45 (protein tyrosine phosphatase receptor type C) is a common leukocyte antigen facilitating cell activation. There are various isoforms of this enzyme. The naïve $\mathrm{T}$ lymphocytes express the longer CD45 isoform and are usually positive for CD45RA. The deletions of certain exons produce a shorter CD45RO isoform that facilitates T-cell activation and is characteristic of the activated memory T-lymphocytes. In our study a significantly lower percentage of CD4+CD45RA+ was found, compared to the controls. Regarding the CD4+CD45RO+ Tcells, a similar phenomenon was not seen. Both tested subsets were evidently reduced in severe forms of MSF and a marked down sloping tendency was noted from mild to severe disease forms. An explanation for the reduced percentage of the naïve T-lymphocyte subsets might be the accelerated activation processes upon antigen presentation, likely more manifested in severe forms of MSF. A probable explanation for the low levels of activated memory T-lymphocytes in severe MSF could be their massive shift to the perivascular tissues.

\section{CONCLUSIONS}

T-lymphocytes are important for the effective host defense against invasive rickettsiae in vivo. Perivascular infiltrates by T-lymphocytes and macrophages release a large amount of cytokines, which activate the infected endothelial cells and tissue phagocytic cells by enhancing their potential to kill the intracellular pathogens. Our study suggests that the reduced T-lymphocyte percentage in the peripheral blood of patients with MSF are likely attributable to the cell migration into the perivascular inflammatory infiltrates. This hypothesis is supported by the fact that the decreased $\mathrm{T}$-cell percentages were more pronounced in severe forms of MSF, where the rickettsial pathogen was presumably present in the largest quantity and greatest expansion into tissue and organ microvasculature. Such investigations could provide an indirect assessment of T-lymphocyte distribution in the perivascular space. Increased percentage of $\mathrm{T}$ lymphocytes with activation markers might be associated with the control of rickettsial infection as well. In both cases, relationships with the disease severity were established. In this respect, an important issue of this study is the possible prognostic value of T-cell subset percentages in the peripheral blood of MSF patients, predicting an evolution of the clinical condition to a clinical form, according to the severity of disease.

\section{The authors declare no conflict of interest.}

\section{REFERENCES}

1. Rovery C, Brouqui P, Raoult D. Questions on Mediterranean spotted fever a century after its discovery. Emerg Infect Dis, 14:1360-1367, 2008.

2. Demeester R, Claus M, Hildebrand $M$ et al. Diversity of life-threatening complications due to Mediterranean Spotted Fever in returning travelers. Journal of Travel Medicine, 17(2):100-104, 2010.

3. Sahni S, Rydkina E. Host-cell interact with pathogenic Rickettsia. Future Microbiol,4:323-39,2009.

4. Baltadzhiev I, Murdjeva M. Levels of certain endothelial biomarkers during the acute phase and convalescence in patients with different severity of Mediterranean spotted fever. Folia Medica, 55(3\&4):1725, 2013.

5. Valbuena G, Feng HM, Walker DH. Mechanisms of immunity against rickettsiae: new perspectives and opportunities offered by unusual intracellular parasite. Microbes Infect, 4:625-633, 2002.

6. Dign-George F, Tissot-Dupon H, Grau G et al.Differences in level of soluble E-selectin \& VCAM-1 in malignant vs non malignant Mediterranean spotted fever. Thromb Haemost, 82:1610-1613, 1999.

7. Kuss I, Hathaway B, Ferris $\mathrm{R}$ et al. Decreased absolute counts of T lymphocyte and their relation to disease in squamous cell carcinoma of the head and neck. Clin Cancer Res, 10(11):3755-3762, 2004.

8. Gospodinova $M$. Changes in the Tlymphocytes (CD3+CD19-) and activated $\mathrm{T}$ - lymphocytes (CD3+HLA-DR+) in patients over 60 with Mediterranean spotted fever. European Medical, Health and Pharmaceutical Journal, 2:31-35, 2011. 
9. Baltadzhiev IG, Popivanova NI, Stoilova YM, Kevorkian AK. Mediterranean spotted fever - classification by disease course and criteria for determining the disease severity. Folia Medica, 54(4):53-61, 2012.

10.Alexandrova D, Alexandrov E: Laboratory diagnostics of rickettsial diseases. In: Contemporary state of the rickettsioses in the world and in Bulgaria. E. Alexandrov, J. Kazar, K. Hechemy (eds.) "Prof. Marin Drinov" Academic Publish House. Sofia, 315-327, 2007.

11. Malavasi F, Deaglio S, Funaro A. Evolution and function of the ADP ribosyl cyclase/CD38 gene family in physiology and pathology. Physiol Rev, 88:841-886, 2008.

12.Linsley PS, Ledbetter JA The role of the CD28 receptor during $\mathrm{T}$ cell responses to antigen. Annu Rev Immunol, 11:191-212, 1993.

13.Feng H, Popov VL, Yuoh G, Walker DH. Role of T lymphocyte subsets in immunity to spotted fever group Rickettsiae. $J$ Immunol, 158(11):5314-5320, 1997.

14. Walker DH, Olano JP, Feng HM. Critical role of cytotoxic $\mathrm{T}$ lymphocytes in immune clearance of rickettsial infection. Infect Immun, 69:1841-1846, 2001.

15.Cillari E, Milano S, D'Agostino P, et al. Depression of CD4 $\mathrm{T}$ cell subsets and alteration in cytokine profile in boutonneuse fever. $J$ Infect Dis, 174(5):1051-1057, 1996.

16.Herrero-Herrero JI, Ruiz-Beltran R, Cordero M. T lymphocyte subsets in Mediterranean spotted fever. Acta Trop, 45(3):195-202, 1988.

17. Walker DH, Ismail N. Emerging and reemerging rickettsioses: endothelial cell infection and early disease events. Nat Rev Microbiol, 6:375-386, 2008.

18. Walker DH, Dumler JS. The Role of CD8 T Lymphocytes in Rickettsial Infections Semin Immunopathol,.37(3): 289-299, 2015.

19.Herrero-Herrero JI, Walker DH, RuizBeltran R. Immunohistochemical evaluation of the cellular immune response to Rickettsia conori in taches noires.J Infect Dis, 155:802-805, 1987.

20.Kim J, Smith K, Naefie $R$ et al. Histopathologic features of and lymphoid population in the skin of patients with the spotted fever group of rickettsiae: Southern Africa. Int J Dermatol 43:188-194, 2004.
21.Manes TD, Pober JS Antigen presentation by human microvascular endothelial cells triggers ICAM-1 -dependent transendothelial protrusion by- and fractalkine dependent transendothelial migration of effector memory CD4+ $\mathrm{T}$ cells. The Journal of Immunology 180:8386-8392, 2008.

22. Choi J, Enis DR, Koh KP, et al. Tlymphocyte endothelial cell interaction. Annu Rev Immunol 22:683-709, 2004.

23.Pober JS. Immunology of human vascular endothelium. Immunol Res, 19:225-232, 1999.

24.Marelli-Berg F, James M, Dangerfield J et al. Cognate recognition of the endothelium induces HY specific CD8+T-lymphocyte transendothelial migration (diaped) in vivo.Blood 103:3111-3116, 2004.

25. Savinov AY, Wong FS, Stonebraker AC, et al. Presentation of antigen by endothelial cells and chemoattraction required for homing of insulin-specific CD8+T cells. $J$ Exp Med 197:643-656, 2003.

26.Baltadzhiev I, Pavlov P. T-lymphocyte Subset Absolute Counts in the Peripheral Blood of Mediterranean Spotted Fever Patients: Relations to Disease Severity. Folia Medica 57 (2):93-103, 2015

27. Mansueto P, Vitale G, Cascio A et al. New insight into immunity and immunopathology of Rickettsial diseases. Clin Dev Immunol, 2012, Article ID 967852, 26 p, doi:10.1155/2012/967852.

28. Mansueto S, Vitale G, Mocciaro C et al. Modifications of general parameters of immune activation in the sera of Sicilian patients with Boutonneuse fever. Clin Exp Immunol, 111(3):555-558, 1998.

29. Gospodinova MD, Nenova MA, Mileva SS. Changes in the activated cytotoxic suppressor T-lymphocytes in elderly patients with Mediterranean spotted fever. Archives: The International Journal of Medicine, 2(3):263-268, 2009.

30. Sandoval-Montes C, Santos-Argumedo L. CD38 is expressed selectively during the activation of a subset of mature $\mathrm{T}$ cells with reduced proliferation but improved potential to produce cytokines. J Leukoc Biol, 77:513-521, 2005.

31.Partidá-Sánchez S, Rivero-Nava L, Shi G, Lund FE. CD38: an ecto-enzyme at the crossroads of innate and adaptive immune responses. Adv Exp Med Biol, 590:171-183, 2007. 
32.Uda $\mathrm{H}$, Mima $\mathrm{T}$, Yamaguchi $\mathrm{N}$, et al. Expansion of a CD28- intermediate subset among CD8 $\mathrm{T}$ cells in patients with infectious mononucleosis. $J$ Virol, 76(13):6602-6608, 2002.

33.Lenschow DJ, Walunas TL, Bluestone JA CD28/B7 system of $\mathrm{T}$ cell costimulation. Annu Rev Immunol, 14:233-258,1996.

34.Harding FA, Allison JP CD28-B7 interactions allow the induction of $\mathrm{CD} 8+$ cytotoxic $\mathrm{T}$ lymphocytes in the absence of exogenous help. J Exp Med, 177 (6):17911796, 1993.

35. Young JW, Steinman RM. Dendritic cells stimulate primary human cytolytic lymphocyte responses in the absence of CD4+ helper $\mathrm{T}$ cells. $J$ Exp Med, 171(4):1315-1332, 1990.
36. Greenfield E, Nguyen K, Kuchroo V. CD28/B7 costimul. Crit Rev Immunol, 18(5):389-418, 1998.

37. Valbuena $G$, Walker DH. Infection of the endothelium by members of the order rickettsiales. Thromb Haemost, 102:10711079, 2009.

38. Bour-Jordan H, Blueston JA. CD28 function: a balance of costimulatory and regulatory signals. J Clin Immunol, 22(1):17, 2002.

39.39. Gamberg J, Pardoe I, Bowmer MI et al. Lack of CD28 expression on HIV-specific cytotoxic T-lymphocytes is associated with disease progression. Immunology and Cell Biology 82:38-46, 2004 